\title{
Impact of Nationwide COVID-19 Lockdown on Indian Air Quality in Terms of Aerosols as Observed from the Space
}

Special Issue:

Special Issue on COVID-19 Aerosol Drivers, Impacts and Mitigation (XII)

\author{
Manoj K. Mishra*, Pradyuman S. Rathore \\ Space Applications Centre, ISRO, Ahmedabad 380015, Gujarat, India
}

\section{ABSTRACT}

Air pollution in India, especially in cities located in Indo-Gangetic plain (IGP), has exceeded all standards in the recent past. The development of an effective pollution control strategy requires knowledge of the pollutant sources, their spatio-temporal variability, and the efficacy of control strategies. The Indian government has implemented nationwide lockdown (LD) during March and April 2020 to contain the infectious disease COVID-19. LD also provides an opportunity to evaluate the efficacy of restricting anthropogenic activities in controlling air pollution. In the present paper, using data from space-borne sensors, a detailed analysis of the impact of LD on aerosols in the Indian atmosphere is presented. The aerosol optical depth (AOD), fine mode fraction (FMF), absorbing aerosol index (AAI), active fire/thermal anomaly and the HYSPLIT model is used to study the instantaneous state and spatio-temporal transportation of aerosols. On average, an overall decrease in AOD with $60 \%$ of the Indian landmass showing an average decrease of 0.16 is observed. A significant decrease in FMF indorses decreased AOD solely due to restricted anthropogenic activities, especially in IGP, which confirms the positive impact of LD on air quality. However, central, northeast and partially western India show some contrasting results which are associated with smoke from active fires. An increase of $30 \%$ in fire spots is observed during LD in these regions. The city-level analysis shows improved air quality in most of the cities located in IGP during LD. The cities located in the west, north-west and east India have shown a small decrease in AOD during LD, while in central, north-east, and few in the southern region, the increased $A O D$ is observed in spite of LD due to increase in biomass burning.

Keywords: COVID-19, Aerosol optical depth, Fine mode fraction, Active fire, HYSPLIT

\section{INTRODUCTION}

The COVID-19 (a disease caused by novel coronavirus 2019) pandemic forced the governments of different countries to shut down the industrial activity and transportation services. Recent studies have shown that COVID-19 induced lockdown (LD) has shown significant improvement in air quality in various parts of China in terms of air quality index and air pollutants including ground-level particulate matter (PM), sulfur dioxide $\left(\mathrm{SO}_{2}\right)$, carbon monoxide (CO), nitrogen dioxide $\left(\mathrm{NO}_{2}\right)$ and ozone $\left(\mathrm{O}_{3}\right)$ (Chen et al., 2020; Filonchyk et al., 2020; Li et al., 2020; Wan et al., 2020; Zhang et al., 2020). Apart from the ground-level PM and pollutant gases, some of these studies also reported a comparative analysis of the spatial and temporal distribution of aerosol optical depth (AOD) and their optical properties (Filonchyk et al., 2020; Li et al., 2020) in different parts of China with and without LD. The impact of LD measure taken in other parts of the world such as countries in middle-east (Broomandi et al., 2020; Faridi et al., 2020; Sahin et al., 2020), South-Asia (Babu et al., 2020; Jain et al., 2020; Li et al., 2020; Metya et al., 2020; Navinya et al., 2020; Suhaimi et al., 2020), north and south-America (Naeger et al., 2020; Zalakeviciute et al., 2020) and Europe (Bessagnet et al., 2020; Tobias et al., 2020) to contain the spread of COVID-19 on air quality has also been reported. All these studies based on data acquired from space-borne as well as ground-based instruments endorses that LD measures taken to contain COVID-19 
pandemic have dramatically reduced the greenhouse gases and PM emissions from factories and transport vehicles leading to low air pollution around the world.

It is expected that the overall concentration and characteristics of aerosol particles in the atmosphere should be affected due to restrictions on human-made emission sources during LD. As far as the impact of COVID-19 LD on air quality in India is concerned, most of the studies are limited to the analysis of ground-based measurements of $\mathrm{PM}$, and pollutant gases $\left(\mathrm{CO}, \mathrm{NO}_{2}, \mathrm{O}_{3}\right.$, and $\mathrm{SO}_{2}$ ) (Babu et al., 2020; Bedi et al., 2020; Jain et al., 2020; Navinya et al., 2020). Thus, a comprehensive analysis of aerosols loading and their optical properties over the Indian region with and without LD measures to contain COVID-19 is still missing. In complex atmospheres such as the case of the Indian atmosphere where aerosol concentration and properties are very dynamic in space-time and are driven by multiple factors (anthropogenic as well as natural), it is very difficult to identify the exact reason for a change in aerosol loading and their properties. Moreover, change in the aerosol field due to restricted anthropogenic sources (mainly biomass/bio-fuel combustion) during the LD period may get cancelled out by natural but similar combustion processes such as forest fire burning or biomass burning in rural areas. On the other hand, the dust particles in terms of size parameter are different from the smoke but are similar in absorbing strength, may sometimes lead to false interpretation. All these facts set the requirement of a detailed study on the aerosol loading, their absorbing properties, as well as some idea on the particle sizes are necessary to interpret the exact impact of LD on aerosols in the Indian atmosphere. Along with this, the exploration of other sources such as dust transportation or fire, etc., that may hide or dwarf the impact of LD on aerosols is a necessity. In the present paper, observations and analysis of the impact of LD on aerosols in the Indian atmosphere are presented based on space-borne sensor datasets, products, and modeling, accounting for all points discussed above. The major objectives of the present work are defined as (a) to study overall, regional and city-level variation of AOD and properties in India before and during LD period, (b) to do evidential study whether the observed trends in AOD are linked to LD or some other sources such as forest fire, and dust transportation, etc., (c) to serve knowledge about the sources that contribute to air pollution, their spatio-temporal variability, and the efficacy of restricting anthropogenic sources as a pollution control strategy in different parts of India.

\section{METHODS}

\subsection{Study Area and Time-period}

The country-wide LD in India was announced on 25 March 2020, after an experimental voluntary public Curfew on 22 March 2020, and subsequent limited LD on 23 and 24 March 2020 (UN News). In the present study, about 6-week time period (01 March-14 April 2020) has been analyzed and divided into three parts namely: (a) 01-21 March is considered as 'pre-lockdown period' (PLDP), (b) 22-24 March 2020 is considered as 'limited lockdown period' (LLDP), and (c) 25 March-14 April 2020 is considered as 'complete lockdown period' (CLDP).

The study areas cover the entire Indian landmass as shown in Fig. 1. The Indian landmass show lot of heterogeneity in terms of urban settlements, the spatial distribution of population, industrialization, forests, aridity, etc., which makes the spatial distribution of atmospheric aerosol very complex. Higher population density, anthropogenic emission sources, and natural conditions (low-elevation, Himalayan range in the north, and seasonal wind pattern) cumulatively make entire Indo-Gangetic plain (IGP) one of the most air polluted regions in south-east Asia. On the other hand, the southern part of India, comparatively having less population is relatively less polluted in terms of PM or aerosol whereas North-East India shows a seasonal peak in aerosol due to forest fires during March, April and May (Ramachandran et al., 2008).

\subsection{Datasets, Modeling, and Methodology}

Numerous satellite products that are sensitive to the amount and properties of aerosols such as AOD, fine-mode-fraction (FMF), absorbing-aerosol index (AAI), active-fire products (FRP) are used and processed as per the requirement to do a comparative analysis of the state of aerosols with and without LD. To study aerosol transportation during the analysis period, the forward trajectory analysis is performed using the National Oceanic and Atmospheric Administration (NOAA) 


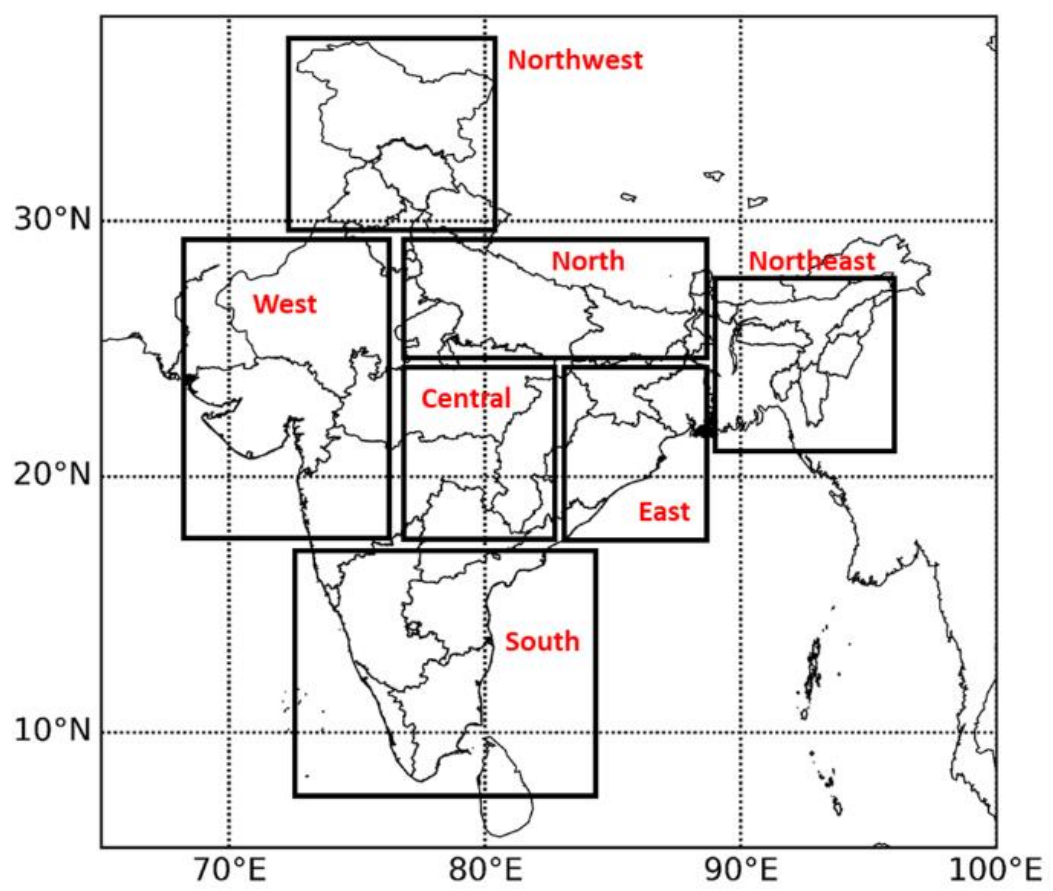

Fig. 1. Study area showing the Indian landmass and adjoining countries. For regional study whole Indian landmass is divided into 7 representative areas represented by rectangles namely, Northwest, West, North, Central, East, Northeast, and South regions.

Air Resource Laboratory's (ARL) Hybrid Single-Particle Lagrangian Integrated Trajectory Model (HYSPLIT) model. Each dataset, data processing method, and model used in this study are described in subsequent paragraphs.

The dark target aerosol product from Visible Infrared Imaging Radiometer Suite (VIIRS) onboard the Suomi National Polar-orbiting Partnership (SNPP) is used in present work (Kaufman et al., 1997; Levy et al., 2007; Sawyer et al., 2018). The VIIRS AOD Level-2 product consists of many layers including spectral AOD (at 470, 550, 650, and $2230 \mathrm{~nm}$ ), FMF, cloud fraction (CF), and corresponding quality flags (QF) (Anderson et al., 2005) at the spatial resolution of $6 \mathrm{~km}$ along swath. The QF is based on the number of valid pixels remained after masking cloudy, bright, and shadow pixels in a retrieval window and based on dark or bright pixel AOD inversion scheme used. The L2 AOD and FMF data are binned to generate daily spatial composites at $0.1^{\circ}$ resolution and then temporal composites for different periods are generated. While compositing only best quality retrieval $(\mathrm{QF}=3$ ) and less cloud contaminated retrievals $(C F<0.75)$ are retained and rest are masked. The composites are generated for different periods for both 2020 and 2019 years.

The AAI product from Sentinel-5P that can detect the elevated layers of absorbing aerosols such as desert dust, biomass burning, and volcanic ash plumes is also used here to get an idea about the type of aerosols. The negative AAI value for non-absorbing particles progressively changes to a positive value for strongly absorbing particles (Zweers et al., 2018). The AAl originally at $5.5 \times$ $3.5 \mathrm{~km}$ resolution are binned at $0.1^{\circ}$ resolution to generate composites for different periods.

The NASA Land-SIPS VIIRS $750 \mathrm{~m}$ active fire product (VIIRS FRP) is used in the present study to identify active fire points (natural forest fire or large-scale human-made biomass burning) and study their impact on aerosols (Csiszar et al., 2014; Csiszar et al., 2016; Li et al., 2018). The VIIRS FRP is used to generate gridded products at $0.1^{\circ}$ resolution in which each grid is filled with the total number of active fire spots detected for the composite time-period. Thus, each grid element of the composite more or less mimics the strength of a particular pixel to act as a source of absorbing fine mode particles (smoke) during the study period.

The HYSPLIT model (Stein et al., 2015; Rolph, 2016) is used to study the transportation of aerosol due to the burning emissions in Indian regions. Previous studies have extensively used HYSPLIT to monitor the influence of fires on air quality in nearby locations (Beegum et al., 2009; Dotse et al., 2016; Kusumaningtyas and Aldrian, 2016). It is known that planetary boundary layer (PBL) 
heights during the pre-monsoon period in central and East Indian regions are higher than $500 \mathrm{~m}$ (Sathyanadh et al., 2017) thus a starting height of 500 meters in HYSPLIT trajectories is used. VIIRS FRP composite is used to identify major burning emission sources and is assumed as source locations in the HYSPLIT model starting on 26 March, 31 March, 5 April and 10 April 2020. Few simulations with source location in the Thar desert is also carried out to see the transportation of desert dust absorbing aerosol during the study period. For each simulation 5 days, forward trajectory with a new trajectory starting at an interval of every 24 hours is generated and analyzed.

\section{RESULTS AND DISCUSSIONS}

\subsection{The Regional and Overall Analysis of Aerosol}

Fig. 2 shows the AOD composites of PLDP and CLDP and for a similar period in 2019. Fig. 2(a) shows an increase in AOD in 2019 during the period corresponding to CLDP. The increasing trend of AOD during the study period is the normal behavior of AOD as it is in agreement with the observations reported by Ramchandran et al. (2008) where analysis of several years of MODIS-terra AOD product was carried out over the Indian region. In contrast to this, from Fig. 2(b) it is very
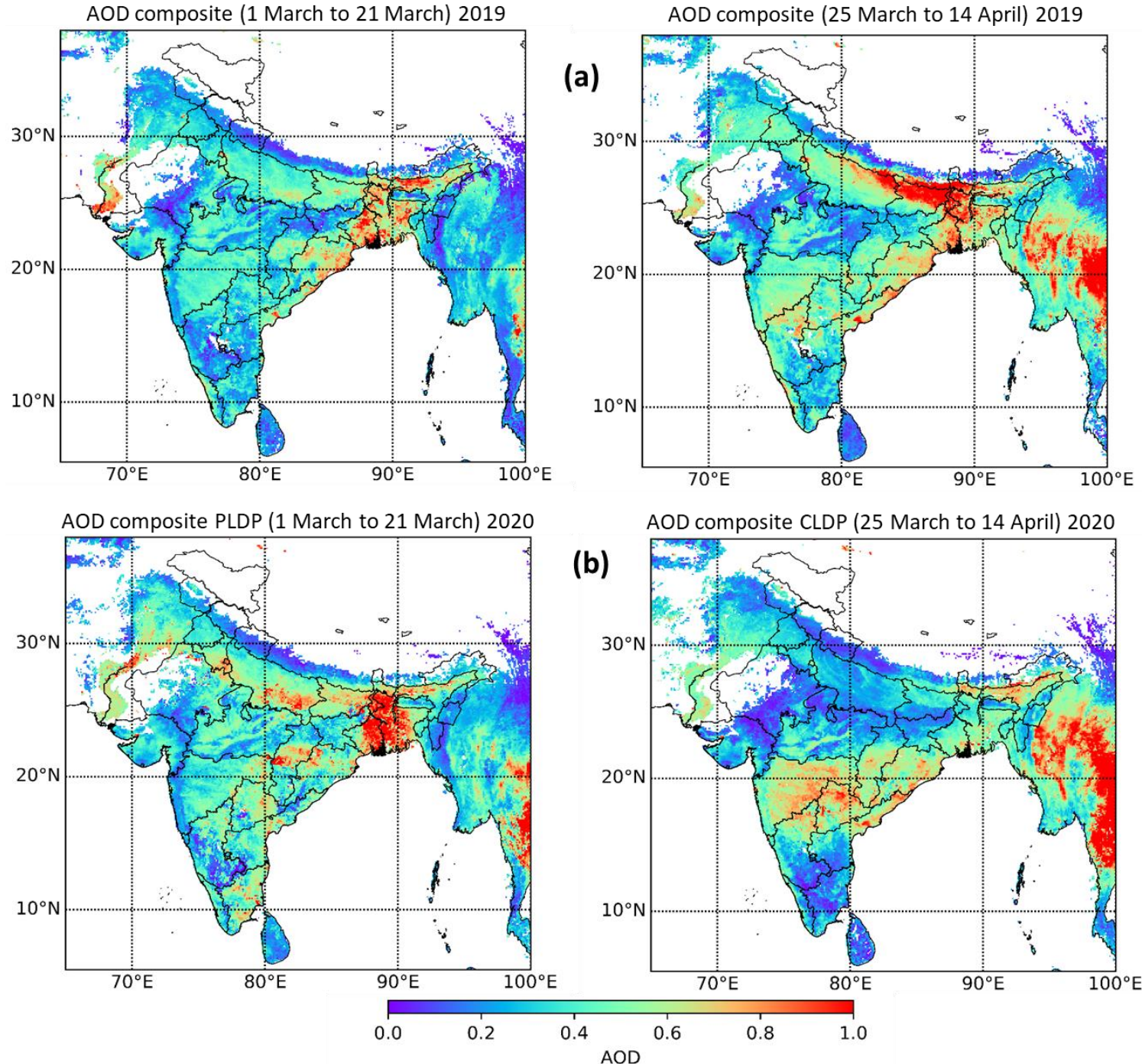

Fig. 2. 01-21 March (PLDP) and 25 March-14 April (CLDP) AOD composites for the year (a) 2019 and (b) 2020. The AOD composite for 2020 shows a clear decrease in Northwest, IG plane, and partially in west India during CLDP, while the 2019 AOD composite shows an increased AOD during CLDP which is a normal seasonal trend. It is to be noted that central India and the northeast do not show the expected decrease in AOD during LD. 
interesting to see that in the year 2020, except central India and extreme Northeast regions, the $A O D$ variations in most of the Indian regions show a reverse trend (decreased AOD during CLDP as compared to PLDP). This reversal AOD trend from historical normal during the study period might be the impact of restricted anthropogenic (fossil-fuel burning and vehicular movement) sources of aerosols during CLDP.

Fig. 3(a) shows the difference between the AOD composites during PLDP and CLDP. Fig. 3(b) show the difference between the AOD composites during the temporal window corresponding to CLDP in 2019 and 2020. In Fig. 3, a positive value refers to a decrease in AOD during CLDP 2020 and vice-versa. The number of pixels with valid AOD retrievals are found to be respectively, 28246 and 27851 for the year 2020 and 2019. Out of these around $60 \%$ and $62 \%$ pixels, have shown a significant drop in AOD of 0.15 and 0.14 (a relative change of $31 \%$ and $29 \%$ ), which may be due to restriction on anthropogenic sources of aerosols during CLDP. This shows that restriction on industrial activities, vehicular movement, and biomass burning may significantly improve the air quality by decreasing the aerosol concentration in entire IGP, southern, and partially western India. However, at the same time, almost $40 \%$ of the pixels show an increase in AOD in spite of LD restrictions, which is different from the normal expectation (Table S1). The analysis of AOD composites over seven different regions (Fig. 1) tabulated in Table 1 shows that most of the pixels with increased AOD during CLDP fall in the central and northeast India with an average relative increase in AOD of around $-4 \%(-24 \%)$ and $-10 \%(-8 \%)$, respectively when compared to PLDP (CLDP time-window) AOD for the year 2020 (2019). The other five regions show a decrease in AOD with a significant average relative change of $17 \%(27 \%)$ and $30 \%(43 \%)$ in northwest and north regions, while east, west, and south regions show a decrease in AOD by only about $5 \%$. From seven-day AOD composite images (see Fig. S1) it is found that even though there is a clear drop in AOD during CLDP over Indian landmass (except for the central, northeast, and partially west India) the decrease in AOD is not monotonic after LD was imposed. In fact, in the absence of anthropogenic sources, the high variability of driving forces of natural aerosol sources may cause significant fluctuation in AOD. This is the main reason for taking long temporal window of about 21 days as the AOD compositing period before and during LD. A shorter composite period may lead to flawed quantitative analysis of the impact of LD on aerosols especially in Indian region where aerosol sources are of mixed nature.

(a) Relative change in $A O D$ during CLDP

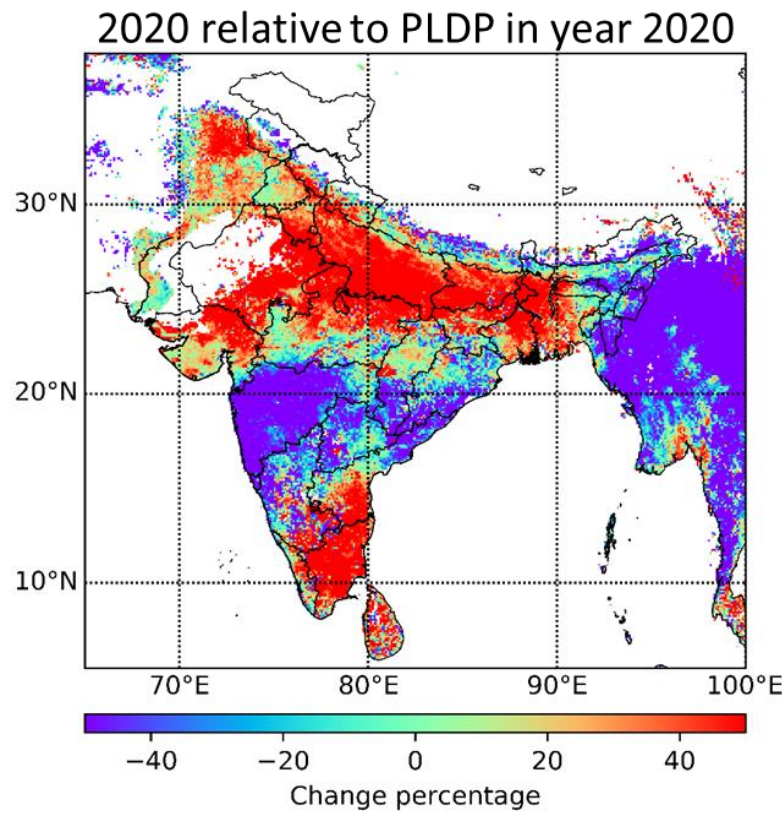

(b) Relative change in AOD during CLDP 2020 relative to similar period in 2019.

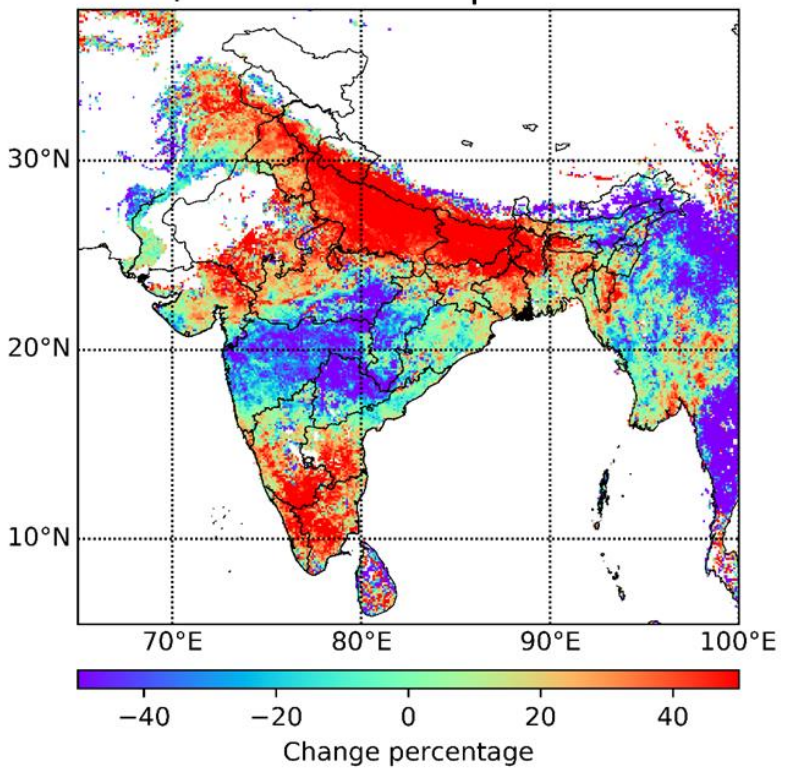

Fig. 3. (a) Relative change in AOD during CLDP 2020 period assuming PLDP AOD as reference defined by relation [100 $\times$ (PLDP AOD 2020 - CLDP AOD 2020)/PLDP AOD 2020]. (b) Relative change in AOD during CLDP 2020 but assuming a similar time window in 2019 as reference. 
Table 1. Regional comparison of average of AOD composite during CLDP with PLDP AOD in 2020 and with average AOD in 2019 during time-window similar to CLDP. Symbol AODd,yy refers to mean AOD for year yy (20 for 2020 and 19 for 2019) and duration $d$ (PLDP or CLDP). Symbol $\varepsilon_{20-20}=\left(A_{\text {PODP }, 20}-\mathrm{AOD}_{\mathrm{CLDP}, 20}\right) / \mathrm{AOD}_{\mathrm{PLDP}, 20}$ and $\varepsilon_{19-20}=\left(\mathrm{AOD}_{\mathrm{CLDP}, 19}-\mathrm{AOD}_{\mathrm{CLDP}, 20}\right) / \mathrm{AOD}_{\mathrm{PLDP}, 19}$ desCribes the relative change in AOD during CLDP.

\begin{tabular}{|c|c|c|c|c|c|}
\hline Region & AODPLDP,20 & $\mathrm{AOD}_{\mathrm{CLDP}, 20}$ & $\mathrm{AOD}_{\mathrm{CLDP}, 19}$ & $\varepsilon_{20-20}$ & $\varepsilon_{19-20}$ \\
\hline Northwest & 0.35 & 0.29 & 0.39 & 17 & 27 \\
\hline West & 0.38 & 0.37 & 0.36 & 5 & 0 \\
\hline North & 0.46 & 0.32 & 0.56 & 30 & 43 \\
\hline Central & 0.44 & 0.46 & 0.37 & -4 & -24 \\
\hline East & 0.49 & 0.48 & 0.53 & 2 & 9 \\
\hline South & 0.36 & 0.34 & 0.41 & 6 & 17 \\
\hline Northeast & 0.49 & 0.54 & 0.50 & -10 & -8 \\
\hline
\end{tabular}

In dark target algorithm for aerosol retrieval, the aerosol mass is assumed to be the mixture of two size mode particles: (a) the coarse mode generally generated by natural mechanical processes such as mineral dust due to wind erosion and sea salt over a rough sea surface and (b) the fine mode particles are generated by combustion and/or gas to particle conversion (Anderson et al., 2005; Kaufman et al., 2005). The fine mode aerosols are believed to be dominant over urban, industrialized and densely populated regions due to fossil fuel burning in vehicles, power plants, households cooking activities and industries. Thus, a decrease in FMF during CLDP is expected if anthropogenic activities play a major role in aerosol generation in the Indian context. Figs. 4(a) and 4 (b) shows the difference in FMF between CLDP and PLDP and the same thing but for the year 2019, respectively. From Fig. 4 and Table 2, it is found that except for the northeast region all other regions show a decrease in FMF in CLDP, but this is true for both years 2019 and 2020. Thus, the decrease in FMF in the Indian region from March to April is a seasonal phenomenon. However, it is notable that in 2020 the decrease in FMF is higher than that for 2019, with contrasting results for northwest and west where FMF in 2020 shows less decrease as compared to that in 2019. The large decrease in FMF during CLDP in 2020, especially in IGP can be associated with decreased human-made combustion processes. Among all regions, the north shows a significantly larger decrease (0.53) in FMF relative to that for 2019 (0.36). This observation supports the fact that LD in the northern region which is having high population density with a huge amount of fossil fuel/biomass burning (large vehicular movement and industrial activities) must show a significant decrease in FMF along with a decrease in AOD. Thus, the significant decrease in AOD and a higher rate of decrease in FMF especially in the entire IGP during CLDP as compared to PLDP confirms the positive impact of LD on air quality in terms of aerosol loading and their characteristics. However, central, northeast and partially western India do not show improvement in air quality during LD, which requires further investigation.

Figs. 5(a) and 5(b) show composites images of VIIRS FRP during the study period, wherefrom it is seen that during CLDP the active fire spots are drastically increased by about $22 \%$ as compared to that during PLDP. Out of the seven regions shown in Fig. 1, the central, east, northeast, and lower part of west encompassing Maharashtra show a dramatic increase in fire points during CLDP. The central, northeast and partially western Indian regions cumulatively show an increase of about $30 \%$ in fire spots during LD. This can influence the aerosol concentration and characteristics in these regions, especially the absorbing strength as smoke (carbonaceous particle) emitted from fires are strongly absorbing in nature and can cancel out the impact of LD on aerosol in totality. This might be a reason for reverse trend (increase in AOD and less decrease in FMF) in some parts of India in spite of decreased industrial and bio-fuel combustion activities during CLDP. The AAI composite for CLDP and PLDP and the difference, shown in Figs. 5(c), 5(d), and 5(e), respectively. From Figs. 5(c), 5(d), and 5(e), a decrease in scattering strength (or increased absorbing strength) of aerosols is apparent during LD which supports the presence of smoke aerosols due to increased active fire points. However, AAl images over the Thar desert show positive AAl values which confirms the presence of elevated absorbing mineral dust aerosols which may also get transported due to wind and may affect the characteristics of aerosols in these regions. 
(a) Difference between mean FMF during PLDP (1 to 21 March) and CLDP (25 March to 14 April) in year 2020

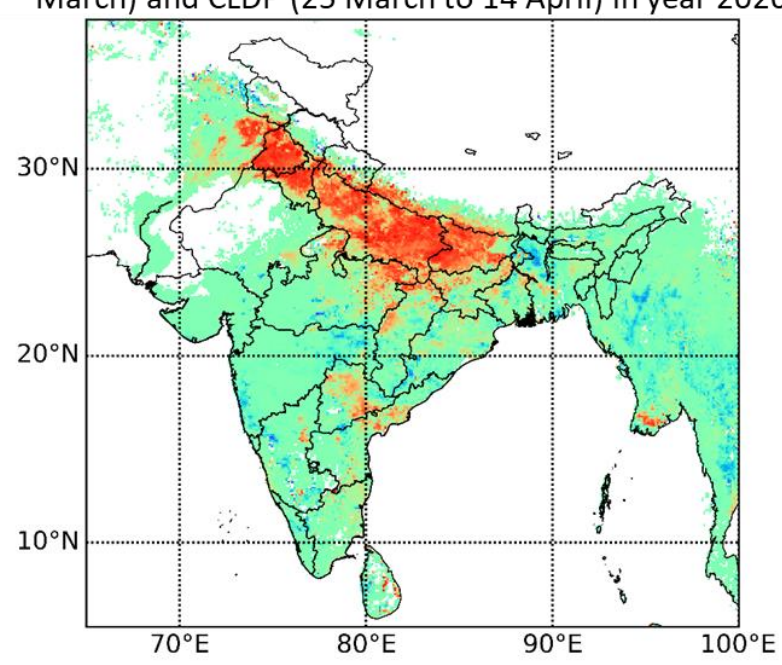

(b) Difference between mean FMF during 1 to 21 March and 25 March to 14 April in year 2019

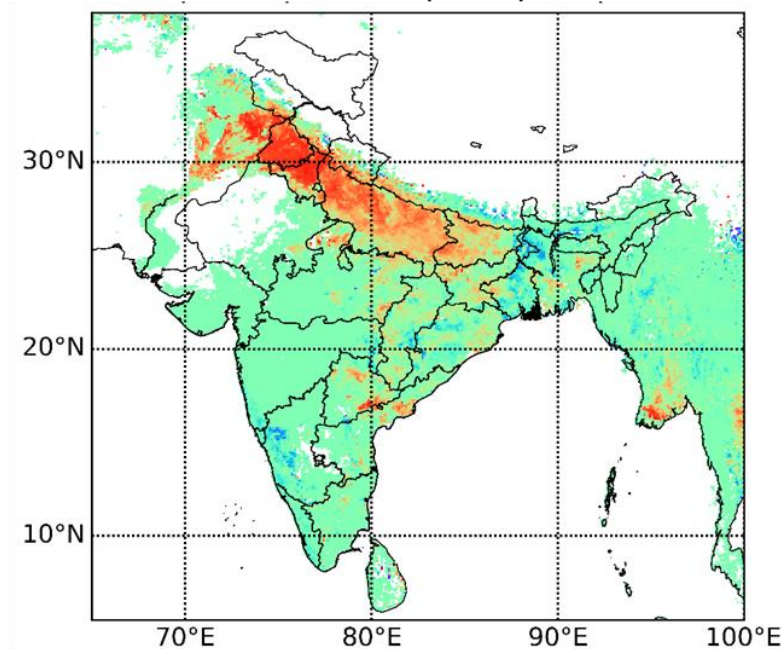

$\begin{array}{llllll}-1.00-0.75-0.50-0.25 & 0.00 & 0.25 & 0.50 & 0.75 & 1.00\end{array}$

Fig. 4. (a) Difference between PLDP and CLDP Fine mode fraction composite for the year 2020. (b) Similar to the left panel but for the same time-windows in the year 2019. Both show that decreasing FMF during the study period is a seasonal trend. However, it is noted that in 2020 during LD the FMF decreased more strongly especially in IGP as compared to that in 2019, this can be associated with an additional decrease in FMF due to restricted anthropogenic activities in densely populated IGP.

Table 2. Regional comparison of average of AOD composite during CLDP with PLDP AOD in 2020 and with average AOD in 2019 during time-window similar to CLDP. Symbol AOD $_{d, y y}$ refers to mean AOD for year yy (20 for 2020 and 19 for 2019) and duration $d$ (PLDP or CLDP). Symbol $\varepsilon_{20-20}=$ $\left(A_{O P D P P, 20}-\mathrm{AOD}_{\mathrm{CLDP}, 20}\right) / \mathrm{AOD}_{\mathrm{PLDP}, 20}$ and $\varepsilon_{19-20}=\left(\mathrm{AOD}_{\mathrm{CLDP}, 19}-\mathrm{AOD}_{\mathrm{CLDP}, 20}\right) / \mathrm{AOD}_{\mathrm{PLDP}, 19}$ describes the relative change in AOD during CLDP.

\begin{tabular}{lll}
\hline Region & $\Delta F M F_{2020}$ & $\Delta F M F_{2019}$ \\
\hline Northwest & 0.35 & 0.40 \\
West & 0.02 & 0.03 \\
North & 0.53 & 0.36 \\
Central & 0.08 & 0.06 \\
East & 0.12 & 0.08 \\
South & 0.04 & 0.01 \\
Northeast & -0.01 & -0.01 \\
\hline
\end{tabular}

Using VIIRS FRP and AAI composite we selected 5 naturally absorbing aerosol sources: Source-1 located at $21.94^{\circ} \mathrm{N}, 86.35^{\circ} \mathrm{E}$ in the forest region of Mayurbhanj, Orissa (Active fire spots), Source-2 located at $19.17^{\circ} \mathrm{N}, 80.38^{\circ} \mathrm{E}$ in the forest region of Bijapur, Chhattisgarh (Active fire spots), Source-3 located at $19.94^{\circ} \mathrm{N}, 73.49^{\circ} \mathrm{E}$ in the forest region of Umbharande, Maharashtra (Active fire spots), Source-4 located at $22.51^{\circ} \mathrm{N}, 93.08^{\circ} \mathrm{E}$ in the forest region of Mayurbhanj, Orissa (Active fire spots), and Source-5 located at $27.06^{\circ} \mathrm{N}, 71.63^{\circ} \mathrm{E}$ in the desert region of Rajasthan (Positive AAI index). These emission source locations are used in HYSPLIT model simulations for forward trajectory analysis to see if atmospheric conditions governing aerosol transportation may affect other parts of India. The initialization height of around 500 meters and Global Forecast System archived data (NOAA/GFSOP25) at a spatial resolution of 0.25 arc degrees is used and 120 hours ( 5 days) forward trajectory is modeled. From Fig. 6 , it is clear that the active fires located in central, east and west (source-1, 2, 3) India seems to affect entire Indian landmass especially the central, lower west, east and northeast regions where an increase in AOD during LD is observed even after restriction on the human-made combustion processes (mainly due to industrial activity and vehicular movement). Moreover, the water vapor in appropriate atmospheric 

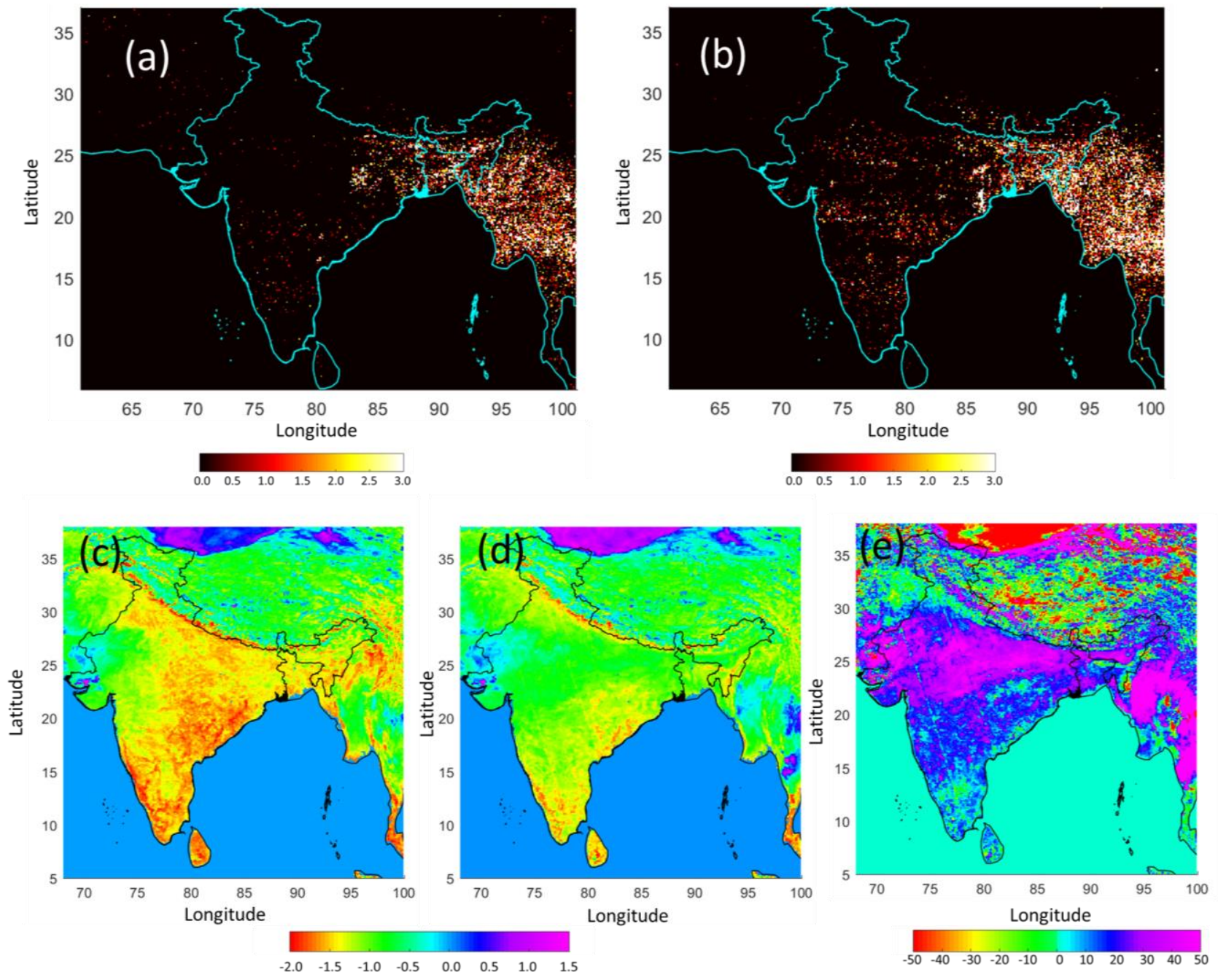

Fig. 5. (a) and (b) show active fire points during PLDP and CLDP, respectively. A drastic increase in fire points is observed in central, east, northeast, and west (Maharashtra) India during CLDP. (c) and (d) show AAl composite for PLDP and CLDP. (e) relative difference image of AAI.

condition conditions may also get condensed over fine mode particles from fires (smoke) thereby severely reducing the visibility and increasing overall atmospheric optical depth. Fig. S2 shows VIIRS true-color image overlaid with day-night active fire points on 31 March 2020 retrieved from VIIRS on-board Suomi and NOAA-20 satellite, where it is seen that smoke from active fire spots has covered entire central, east and lower west India, leading to thick haze layer over these regions. Coarse mode mineral dust (source-5) seems to impact aerosols in western India and IGP, which might be the reason for slightly increased AAI in IGP. The fire points in north-east (around sources-4) do not seem to impact the Indian mainland, instead, trajectory shows eastward transportation of smoke.

Thus, from the analysis results of fire activity, AAI, and HYSPLIT model, it can be concluded that the increased biomass burning/forest fire emissions during CLDP have dwarfed the positive impact of LD on air quality in Maharashtra, Madhya Pradesh and Odisha and partially in adjoining regions. The aerosols from the active fire do not seem to affect the north, northwest, upper west, and lower south regions, and therefore in these regions, a decrease in AOD is observed during CLDP as a result of decreased anthropogenic sources of aerosols.

\subsection{City-level Analysis of Aerosol}

Country-level LD mainly restricted vehicular movement, industries, and other human activities that involve fossil-fuel or biomass burning. The majority of these sources are located in urbanized 


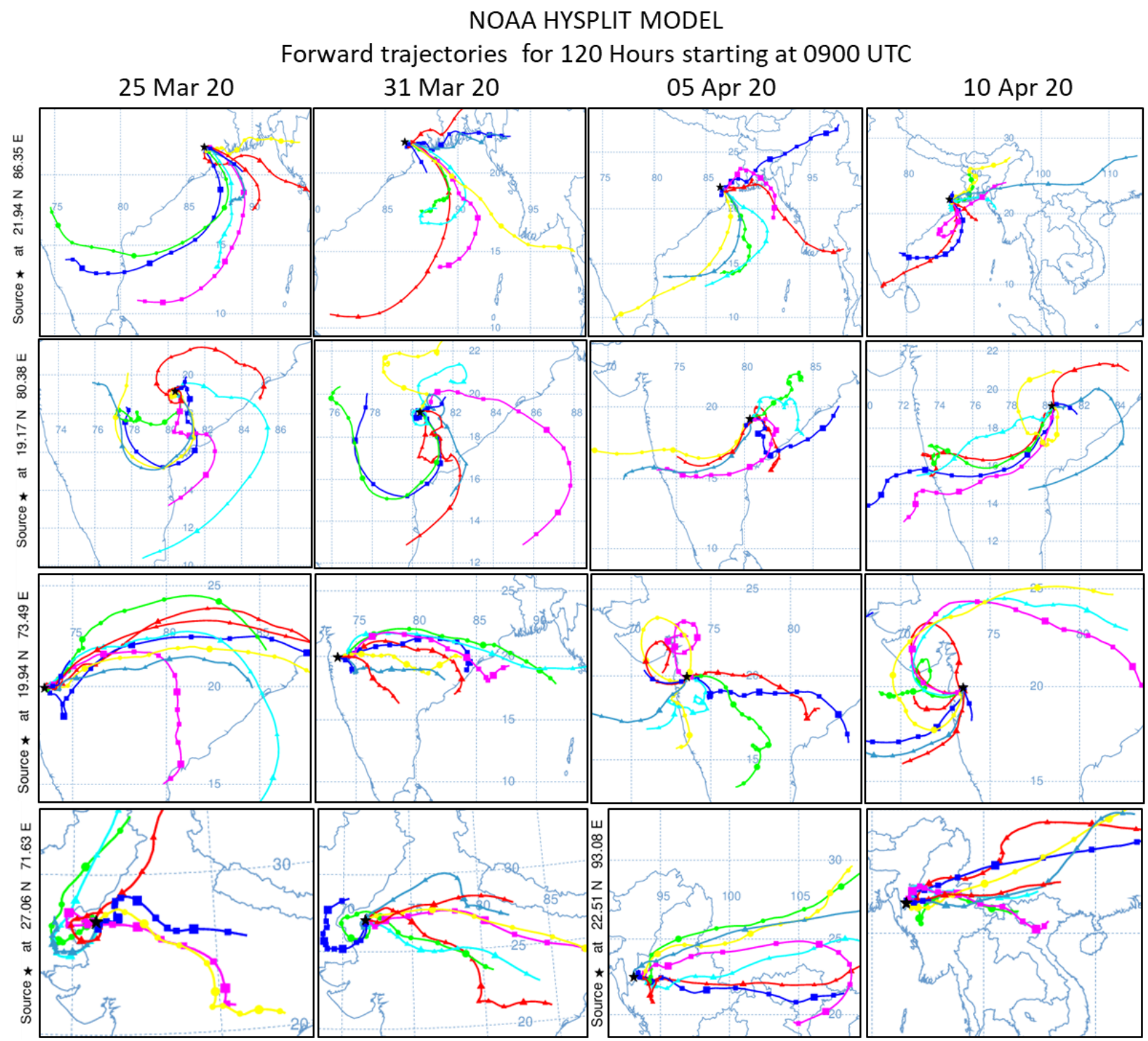

Fig. 6. HYSPLIT forward trajectories. The 25 Mar, 31 Mar, 05 Apr, and 10 Apr 2020 are the start date of the trajectory. Different colors show trajectory started at the 24-hour interval from the start date. The emission source location is represented by black star shape. It is observed that biomass burning or forest fire may have affected the aerosol load and properties in states located in the lower-west (Maharashtra), central (Madhya Pradesh, Chhattisgarh) and eastern India.

cities of India, therefore, though the regional level study in the previous section provides a broad picture of aerosol, city-level analysis is necessary because these are expected to be affected most.

Fig. 7(a) shows mean AOD for periods corresponding to CLDP in 2019 (blue), PLDP 2020 (green), and CLDP 2020 (yellow), while Fig. 7(b) shows the difference between mean AODs. Mumbai (lower west), Hyderabad (south), Bhopal (central) Guwahati (north-east), and Imphal (north-east) are the major cities that do not show a decrease in AOD during CLDP instead they show a significant increase in AOD, which is similar to normal situation as if there is no LD or restrictions (Ramachandran et al., 2008). In north-east cities, this observation is not surprising because due to the low risk of COVID-19 during the study-period considered here, the restrictions on anthropogenic sources may not be too strict and also increase in active fire spots might have increased the AOD. While in cities like Hyderabad, Mumbai, and Bhopal probably due to very high population density the reduction in AOD due to LD may not be so significant and transported aerosol due to fire activities may have canceled out the change on AOD due to LD as seen from space. Fig. S3 shows the 7-day composite time series bar plot of mean AOD during PLDP and CLDP over major cities of India, wherefrom a similar conclusion can be made. 

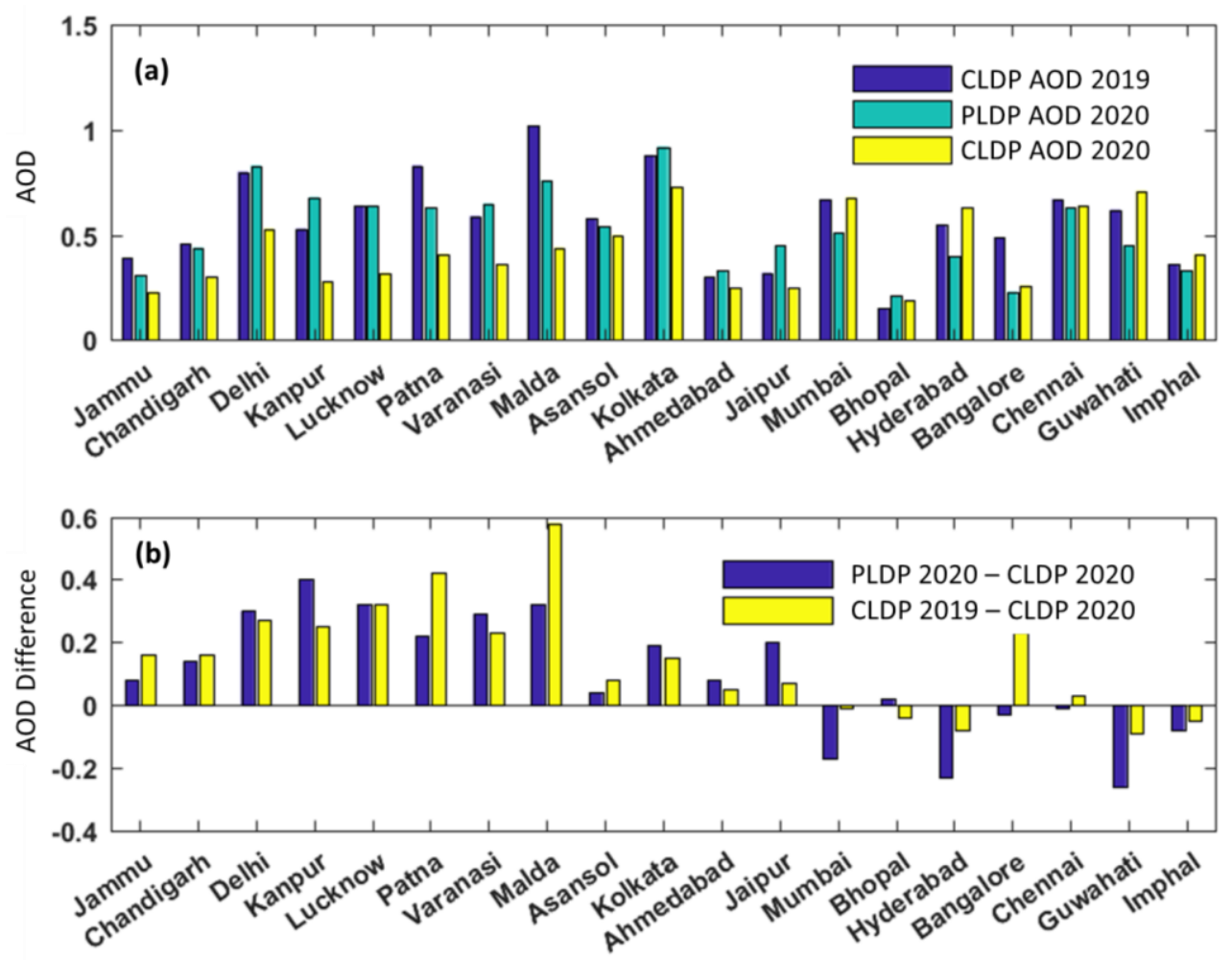

Fig. 7. (a) Mean AOD during different periods of 2020 and 2019, to see the impact of LD over major cities of India. (b) Bar plot of mean AOD difference.

It is clear from the city-level analysis that the cities located in the north show a very strong positive impact of LD on air quality (decreased aerosol during CLDP) as it is a very densely populated region. The restriction in this region led to a sudden drop in anthropogenic aerosols due to human-made combustion processes. The cities located in west, north-west, and east regions, to some extent, also show a decreased $A O D$, but since these regions have less population thus less strong impact of reduced human-made combustion processes can be seen. As evident from fire spots and AAI analysis, cities located in central, north-east, and few in the south and east Indian region show poor air quality even after LD was imposed due to increase in AOD by natural fire activities.

\section{SUMMARY AND CONCLUSIONS}

The spatial and temporal composite data of AOD, FMF, and active-fire from VIIRS, AAI from Sentinel-5P, and forward trajectories simulated using the HYSPLIT model are used to analyze the spatio-temporal variability, sources, and transportation of aerosols in Indian atmosphere before and during LD period. The focus of the study is to understand and to do an assessment of the impact of COVID-19 LD event on air quality and to evaluate the efficacy of policies that may involve restricting anthropogenic aerosol sources for controlling air pollution in India especially in metro cities. Following are the salient results and conclusions of the study:

(a) About $60 \%$ of the Indian landmass region shows an average decrease of 0.16 in AOD value during complete LD. A significant decrease in FMF especially in Indo-Gangetic plain is solely due to reduced industrial activity and vehicular movements as a result of complete LD, leading to improved air quality.

(b) Contrasting to most of the Indian landmass, central, north-east, and partially western India does not show decrease in AOD in spite of LD, in fact, some parts show a clear increase in AOD. Investigation of active fire, aerosols characteristics, and aerosol transport modeling in these regions indicate that this contrasting behaviour is associated with the emission of carbonaceous aerosols from active fires. 
(c) The aerosols from the active fire do not seem to affect the north, northwest, upper west, and lower south where a significant decrease in AOD during LD is observed.

(d) The city-level analysis concludes that LD has improved the air quality in terms of decreased aerosol concentration in cities located in northern India. The cities located in the west, Northwest and East region show a weak but positive impact on air quality. Cities located in central, north-east, and few in the south and east Indian region show negative results associated with fire activity.

(e) Seven-day AOD composite though shows a decrease in AOD during LD but also shows fluctuations in $A O D$, suggesting that apart from anthropogenic activities, the natural sources of aerosol and their driving forces play a major role in the variability of atmospheric aerosol. This may lead to flawed analysis if a very small period or specific day only AOD is used for the study. An important conclusion based on this study is that restriction on human-made aerosol sources such as industrialization and fossil fuel/biomass combustion in a phased manner can be an effective strategy for controlling the air pollution as observed in the northern region of India due to $L D$, but at the same time given strategy may not show expected results in seasons when fire activity occurs, for example, the central and adjoining region of India during March-April months as observed in the present study. Based on this a similar conclusion can be made for the case of northern India during the November-December period when a large amount of agriculture residue burning occurs in states of Haryana, Punjab, \& adjoining states.

\section{ACKNOWLEDGMENTS}

We would like to acknowledge Dr. Praveen K Gupta, Dr. Arundhati Misra, and Dr. RP Singh for invaluable discussions. We would also like to thank Dr. Raj Kumar for his support. We also acknowledge the LAADS DAAC - NASA website (https://ladsweb.modaps.eosdis.nasa.gov/) from where maximum data used in this work is downloaded free of cost.

\section{DISCLAIMER}

The views and opinions expressed in this paper are those of the authors and should not be interpreted as an official ISRO or Government of India position, policy, or decision.

\section{SUPPLEMENTARY MATERIAL}

Supplementary data associated with this article can be found in the online version at https://doi.org/10.4209/aaqr.2020.07.0461

\section{REFERENCES}

Anderson, T.L., Wu Y., Chu, D.A., Schmid, B., Redemann, J., Dubovik O. (2005). Testing the MODIS satellite retrieval of aerosol fine-mode fraction. J. Geophys. Res. 110, D18204. https://doi.org/10.1029/2005JD005978.

Babu, S.R., Rao, N.N., Kumar, S.V., Paul, S., Pani, S.K. (2020). Plausible role of environmental factors on COVID-19 transmission in the megacity Delhi, India. Aerosol Air Qual. Res. 20, 20752084. https://doi.org/10.4209/aaqr.2020.06.0314

Beegum, S.N., Moorthy, K.K., Babu, S.S., Satheesh, S.K., Vinojb, V., Badarinath, K.V.S., Safai, P.D. Devara, P.C.S., Singh, S., Vinod, Dumka, U.C., Pant, P. (2009). Spatial distribution of aerosol black carbon over India during pre-monsoon season. Atmos. Environ. 43, 1071-1078. http://dx.doi.org/10.1016/j.atmosenv.2008.11.042

Bessagnet, B., Siour, G., Mailler, S., Pennel, R., Cholakian, A. (2020). Impact of lockdown measures to combat COVID-19 on air quality over western Europe. Sci. Total Environ. 741, 140426. https://doi.org/10.1016/j.scitotenv.2020.140426

Broomandi, P., Karaca, F., Nikfal, A., Jahanbakhshi, A., Tamjidi, M., Kim, J.R. (2020). Impact of 
COVID-19 event on the air quality in Iran. Aerosol Air Qual. Res. 20, 1793-1804. https://doi.org/10.4209/aaqr.2020.05.0205

Chen, Q.X., Huang, C.L., Yuan, Y., Tan, H.P. (2020). Influence of COVID-19 event on air quality and their association in Mainland China. Aerosol Air Qual. Res. 20, 1541-1551. https://doi.org/10.4 209/aaqr.2020.05.0224

Csiszar, I., Schroeder, W., Giglio, L., Ellicott, E., Vadrevu, K.P., Justice, C.O., Wind, B. (2014). Active fires from the Suomi NPP Visible Infrared Imaging Radiometer Suite: Product status and first evaluation results. J. Geophys. Res. 119, 803-816. https://doi.org/10.1002/2013JD020453

Csiszar, I., Schroeder, W., Giglio, L., Mikles, V., Tsidulko, M. (2016). The NOAA NDE Active Fire EDR External Users Manual. https://www.star.nesdis.noaa.gov/jpss/documents/UserGuides/ VIIRS_ActiveFire_EUM.pdf

Dotse, S.Q., Dagar, L., Petra, M.I., De Silvaa, L.C. (2016). Influence of south east Asian haze episodes on high $\mathrm{PM}_{10}$ concentrations across Brunei Darussalam. Environ. Pollut. 219, 337352. https://doi.org/10.1016/j.envpol.2016.10.059

Faridi, S., Yousefian, F., Niazi, S., Ghalhari, M.R., Hassanvand, M.S., Naddafi, K. (2020). Impact of SARS-CoV-2 on ambient air particulate matter in Tehran. Aerosol Air Qual. Res. 20, 1805-1811. https://doi.org/10.4209/aaqr.2020.05.0225

Filonchyk, M., Hurynovich, V., Yan, H., Gusev, A., Shpilevskaya, N. (2020). Impact assessment of COVID-19 on variations of $\mathrm{SO}_{2}, \mathrm{NO}_{2}, \mathrm{CO}$ and $\mathrm{AOD}$ over east China. Aerosol Air Qual. Res. 20, 1530-1540. https://doi.org/10.4209/aaqr.2020.05.0226

Kaufman, Y.J., Tanré, D., Remer, L.A., Vermote, E.F., Chu, A., Holben, B.N. (1997). Operational remote sensing of tropospheric aerosol over the land from EOS-MODIS. J. Geophys. Res. 102, 17051-17067. https://doi.org/10.1029/96JD03988

Kusumaningtyas, S.D.A., Aldrian, E. (2016). Impact of the June 2013 Riau province Sumatera smoke haze event on regional air pollution. Environ. Res. Lett. 11, 1-11. https://doi.org/10.108 8/1748-9326/11/7/075007

Levy, R.C., Remer, L.A., Dubovik, O. (2007). Global aerosol optical properties and application to Moderate Resolution Imaging Spectroradiometer aerosol retrieval over land. J. Geophys. Res. 112, D13210. https://doi.org/10.1029/2006JD007815

Li, F., Zhang, X., Kondragunta, S., Csiszar, I. (2018). Comparison of fire radiative power estimates from VIIRS and MODIS observations. J. Geophys. Res. 123, 4545-4563. https://doi.org/10.102 9/2017JD027823

Li, J., Tartarini, F. (2020). Changes in air quality during the COVID-19 Lockdown in Singapore and associations with human mobility trends. Aerosol Air Qual. Res. 20, 1748-1758. https://doi.org/10.4209/aaqr.2020.06.0303

Li, Z., Meng, J., Zhou, L., Zhou, R., Fu, M., Wang, Y., Yi, Y., Song, A., Guo, Q., Hou, Z., Yan, L. (2020). Impact of the COVID-19 event on the characteristics of atmospheric single particle in the northern China. Aerosol Air Qual. Res. 20: 1716-1726. https://doi.org/10.4209/aaqr.2020.06. 0321

Metya, A., Dagupta, P., Halder, S., Chakraborty, S., Tiwari, Y.K. (2020). COVID-19 lockdowns improve air quality in the South-East Asian regions, as seen by the remote sensing satellites. Aerosol Air Qual. Res. 20, 1772-1782. https://doi.org/10.4209/aaqr.2020.05.0240

Naeger, A.R., Murphy, K. (2020). Impact of COVID-19 Containment measures on air pollution in California. Aerosol Air Qual. Res. 20, 2025-2034. https://doi.org/10.4209/aaqr.2020.05.0227

Navinya, C., Patidar, G., Phuleria, H.C. (2020). Examining effects of the COVID-19 national lockdown on ambient air quality across urban India. Aerosol Air Qual. Res. 20, 1759-1771. https://doi.org/10.4209/aaqr.2020.05.0256

Ramachandran, S., Cheria, R. (2008). Regional and seasonal variations in aerosol optical characteristics and their frequency distributions over India during 2001-2005. J. Geophys. Res. 113, D08207. https://doi.org/10.1029/2007JD008560

Rolph, G.D. (2016). Real-time Environmental Applications and Display SYstem (READY). Online. NOAA Air Resources Laboratory, College Park, MD. http://www.ready.noaa.gov

Şahin, Ü.A. (2020). The effects of COVID-19 measures on air pollutant concentrations at urban and traffic sites in Istanbul. Aerosol Air Qual. Res. 20, 1874-1885. https://doi.org/10.4209/aaq r.2020.05.0239

Sathyanadh, A., Prabhakaran, T., Patil, C., Karipot, A. (2017). Planetary boundary layer height over 
the Indian subcontinent: Variability and controls with respect to monsoon. Atmos. Res. 195, 44-61. https://doi.org/10.1016/j.atmosres.2017.05.010

Sawyer, V.R., Levy, R.C., Mattoo, S., Cureton, G.P., Shi, Y.R. (2018). The VIIRS Dark Target Aerosol Retrieval and Long-Term Continuity from MODIS. AGU Fall Meeting 2018, A31L-3089.

Stein, A.F., Draxler, R.R., Rolph, G.D., Stunder, B.J.B., Cohen, M.D., Ngan, F. (2015). NOAA's HYSPLIT atmospheric transport and dispersion modelling system. Bull. Am. Meteorol. Soc. 96, 2059-2077. https://doi.org/10.1175/BAMS-D-14-00110.1

Suhaimi, N.F., Jalaludin, J., Latif, M.T. (2020). Demystifying a possible relationship between COVID-19, air quality and meteorological factors: Evidence from Kuala Lumpur, Malaysia. Aerosol Air Qual. Res. 20, 1520-1529. https://doi.org/10.4209/aaqr.2020.05.0218

Tobias, A., Carnerero, C., Reche, C., Massagué, J., Via, M., Minguillon, M. C., Alastuey, A., Querol, X. (2020). Changes in air quality during the lockdown in Barcelona (Spain) one month into the SARS-CoV-2 epidemic. Sci. Total Environ. 726, 138540. https://doi.org/10.1016/j.scitotenv.202 0.138540

UN News (2020). COVID-19: Lockdown across India, in line with WHO guidance. https://news.un.org/en/story/2020/03/1060132

Wan, S., Cui, K., Wang, Y.F., Wu, J.L., Huang, W.S., Xu, K., Zhang, J. (2020). Impact of the COVID19 event on trip intensity and air quality in southern China. Aerosol Air Qual. Res. 20, 17271747. https://doi.org/10.4209/aaqr.2020.07.0364

Zalakeviciute, R., Vasquez, R., Bayas, D., Buenano, A., Mejia, D., Zegarra, R., Diaz, A., Lamb, B. (2020). Drastic improvements in air quality in Ecuador during the COVID-19 outbreak. Aerosol Air Qual. Res. 20, 1783-1792. https://doi.org/10.4209/aaqr.2020.05.0254

Zhang, J., Cui, K., Wang, Y.F., Wu, J.L., Huang, W.S., Wan, S., Xu, K. (2020). Temporal variations in the air quality index and the impact of the COVID-19 event on air quality in Western China. Aerosol Air Qual. Res. 20, 1552-1568. https://doi.org/10.4209/aaqr.2020.06.0297

Zweers, D.C.S. (2018). TROPOMI ATBD of the UV aerosol index. Document number: S5P-KNMIL2-0008-RP. https://sentinel.esa.int/documents/247904/2476257/Sentinel-5P-TROPOMI-ATBDUV-Aerosol-Index 